\title{
SPRING LEAF PHENOLOGICAL CHARACTERISTICS OF COMMON LANDSCAPE TREE SPECIES IN NYINGCHI PREFECTURE, TIBET, CHINA
}

\author{
LIU, Z. N. - XU, J.* \\ Resources \& Environment College, Tibet Agriculture \& Animal Husbandry University \\ Tibet, Nyingchi 860000, China \\ (e-mail: 799748121@qq.com; phone:+86-136-2894-7896) \\ *Corresponding author \\ e-mail:872395595@qq.com; phone:+86-136-5894-2629 \\ (Received $3^{\text {rd }}$ Aug 2019; accepted $14^{\text {th }}$ Nov 2019)
}

\begin{abstract}
Studying the phenological characteristics of landscape trees can determine the optimal afforestation time for local landscaping, while also providing a theoretical basis for garden design, plant configuration and garden phenology prediction. In order to grasp the leaf pheniological rhythm of common landscape tree species in Nyingchi Prefecture, optimize the garden plant configuration of Nyingchi Prefecture, 53 kinds of landscape tree species were selected as the object for continuous 5a parallel observation and analysis of their leaf phenology. The results showed that: the budding period lasts from early March to mid-April, and that of 20 species concentrates in late March. It is recommended that afforestation be completed before mid-April. The leaf expansion period lasts from early March to mid-June, and the peak period is from mid-April to early May. It is recommended to arrange the seasonal landscape according to the leaf expansion characteristics of the tree species. The 53 tree species were classified into 5 types based on leaf phenological characteristics. Finally, corresponding measures and suggestions were proposed for local garden afforestation and tree arrangement.
\end{abstract}

Keywords: Tibet, phenological phase, budding, leaf expansion, leaf phenology classification

\section{Introduction}

The phenology of plants refers to their cyclical changes with the climate during annual growth, including budding, branching, leaf expansion, flowering, fruiting, defoliation and dormancy. The external features exhibited by plant organs in different phenological stages are known as phenophase (Zhao et al., 2016). Phenology is often used to study the natural seasonal variation of plants, which has long been valued by biologists (Zhao, 1983). The data for phenological changes can not only provide guidance on afforestation (Wang, 2006; Chang et al., 2011), but also offer certain reference value for optimal configuration of plant landscapes (Yang and Chen, 2000; $\mathrm{Xu}$ et al., 2004; Chen et al., 2011), so that the matching relationship of landscapes between different time periods is coordinated, thus exhibiting the temporal and special beauty of the landscape (Hu et al., 2006; Zhang et al., 2008; Gu and Zhang, 2011).

The dynamic landscape of a region's gardens is, to a large extent, a result of phenological seasonal variations of garden plants. The phenological phases differ for different regions. Studying the phenological changes of local garden plants can provide certain basis and reference for local plant community construction and seasonal landscape, garden plant landscaping. So far, there have been garden phenology related researches mainly in Beijing (Zhang et al., 2018), Shanghai (Zhao et al., 2016), Nanjing (Zhang et al., 2016), Xi'an (Bai et al., 2016), Changchun (Chen et al., 2015), Hengshui (Liu et al., 2013) and Hohhot (Gu and Zhang, 2015), while phenological studies on 
Nyingchi in Tibet Autonomous Region are few. Only a few scholars such as Liu et al. (2015), Xue et al. (2014), Ma et al. (2010), and Wang et al. (2019) have done research from different perspectives of forestry. Study on garden phenology of Nyingchi is extremely scarce. In view of this, with 53 kinds of common landscape trees in Nyingchi as testing pieces, this study researched and analyzed the characteristics of budding and leaf expansion phenology, with a view to providing a useful reference for optimizing the garden plant configuration of Nyingchi Prefecture and upgrading the connotation and quality of garden landscape.

\section{Research method}

\section{Overview of the study area}

The study area is located in Fujian Park and Wetland Park in Nyingchi Prefecture, Tibet (Fig. 1), which is at the densely populated commercial and cultural center of Nyingchi Prefecture. It is located in the lower reaches of the Yarlung Zangbo River in southeastern Tibet $\left(\mathrm{E} 93^{\circ} 25^{\prime}, \mathrm{N} 29^{\circ} 50^{\prime}\right)$, with an elevation of $2,960 \mathrm{~m}$, an average annual temperature of $8.7^{\circ} \mathrm{C}$, an average annual rainfall of $650 \mathrm{~mm}$, an average relative humidity of $71 \%$, annual sunshine hours of $2,022.2 \mathrm{~h}$, a sunshine percentage of $46 \%$ and a frost-free period of $180 \mathrm{~d}$ (Ran et al., 2013).
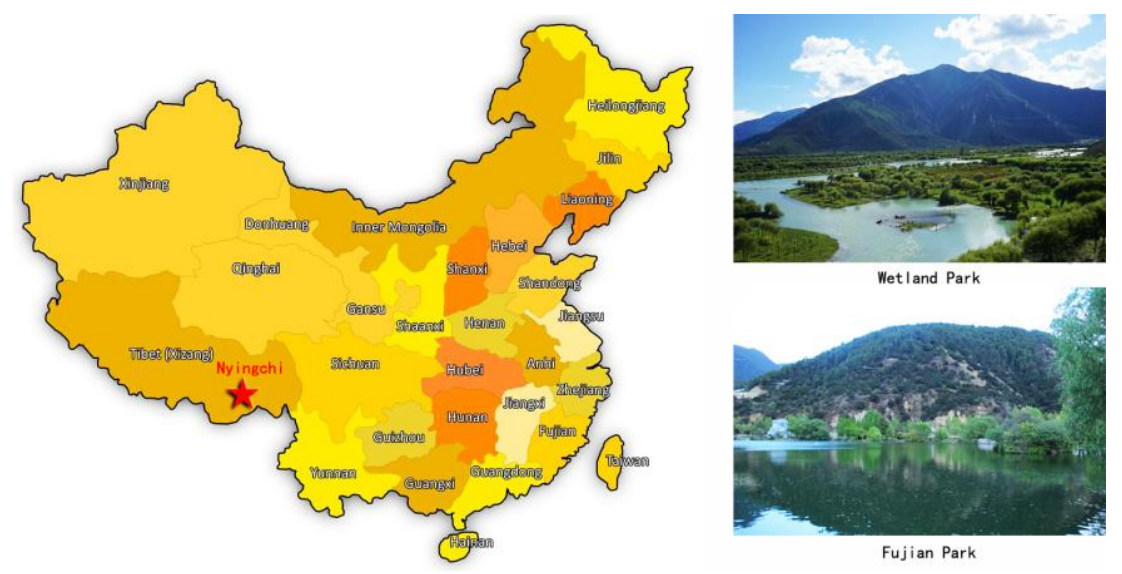

Figure 1. Sample area location and habitat status map

The humid climate belongs to the warm and humid climate zone in southeastern Tibet. Known as the "Snowy Regions South of the Yangtze River", it boasts rich and varied garden plants. The park's greening is mainly native tree species like local wild ornamental seedlings, together with sporadic and small-scale landscape trees introduced from the interior areas. Fujian Park covers an area of $12.4 \mathrm{hm}^{2} .59$ species of woody garden plants were introduced and cultivated from the interior area at its construction (Liu et al., 2015). With the continuous construction of the park, there are 72 species of arbors and 46 species of shrubs in general overall growth. The wetland park covers an area of $35.1 \mathrm{hm}^{2}$. Mainly composed of native plants, the near natural urban forest has 68 species of arbors and 56 species of shrubs in good overall growth. These two parks serve as key city-level parks in Nyingchi Prefecture, which play an important role in improved ecological balance, citizens' recreation and enhanced physical and mental health. 
During the study period (2014-2019), the average annual temperature of the study area is $8.9^{\circ} \mathrm{C}$, the average annual rainfall is $648 \mathrm{~mm}$ and the average relative humidity is $71 \%$. The annual average temperature is slightly higher than previous years, the rainfall and the relative humidity are almost the same as previous years. The climate change has a certain impact on the observation results (Nyingchi, 2014-2019).

\section{Sample selection}

In this study, 53 species of deciduous trees with large planting area, large number and strong group representation were selected as observation objects (Table 1), including 31 species of arbors, 20 species of shrubs and 2 species of vines (which were omitted in this study due to the relatively simple phonological ornamental function of coniferous evergreen species). Three strains of representative plants (middle-aged trees in an open area, enjoying healthy growth without plant disease or insect pests, and with flowering and fruiting for 3a) were selected from each plant type, and the community and soil type, elevation, slope data were recorded.

\section{Observation methods}

According to the "Chinese Phenology Observation Method", the selected 53 species of trees were subject to fixed-strain (marked by tag), fixed-person, regular observation for budding and leaf expansion phenology from March to June of 2014 2019. The observation period was 1 time every $2 \mathrm{~d}$ in the early stage and 1 time every week in the late stage, which lasted for $122 \mathrm{~d}$. To reduce the error, fixed personnel made observations mainly based on visual inspection using combination of tools like telescope, magnifying glass, etc. (Wan et al., 1978; Zhang, 1985). Phenology data were recorded at 14:00-17:00 on the observation day. To facilitate observation and comparison, south side of all samples was selected for observation. To facilitate comparison between different years, all data are preprocessed first, then Julian Day conversion was applied for phenological date, which was to calculate the period from March 1 to the date as Julian Day (Zhu and Wan, 1980).

Phenological observation criteria: the budding period refers to the period when buds of the plants display green leaf opex (in the case of scales, the time shall prevail when scales are cracked to reveal bright colors at the bud top). The leaf expansion period is divided into initial stage of leaf expansion, peak period of leaf expansion and end of leaf expansion. Initial leaf expansion means the buds of individual branches of the observed object show the first batch of flat leaves; peak period of leaf expansion means leaflets on half of the branches of the observed object are completely flattened; end of leaf expansion means over $90 \%$ of the leaflets of the observed object are completely flattened. The duration of leaf expansion refers to the interval between the initial and end of leaf expansion (Wan and Liu, 1979).

\section{Data processing}

Correlation analysis on different parameters in this study was conducted by Pearson correlation coefficient test, and phenological phase load analysis was performed by principal component analysis. Data processing was completed by Excell 2007 and SPSS25.0. In order to facilitate the query and distinguish the phenological phases, the results took $10 \mathrm{~d}$ as the unit in which month was divided into three segments: first, middle and last ten days. 
Table 1. Leaf phenology of common landscape trees in Nyingchi Prefecture

\begin{tabular}{|c|c|c|c|c|c|c|}
\hline \begin{tabular}{c|} 
Serial \\
No.
\end{tabular} & Scientific name & $\begin{array}{l}\text { Budding } \\
\text { period }^{*}\end{array}$ & $\begin{array}{l}\text { Initial stage of } \\
\text { leaf expansion * }\end{array}$ & $\begin{array}{l}\text { Peak period of } \\
\text { leaf expansion }\end{array}$ & $\begin{array}{l}\text { End of leaf } \\
\text { expansion* }\end{array}$ & $\begin{array}{c}\text { Duration of leaf } \\
\text { expansion/d }\end{array}$ \\
\hline 1 & Larix griffithiana & 3.16 & 3.20 & 4.3 & 4.13 & 24 \\
\hline 2 & Metasequoia glyptostroboides & 3.29 & 4.11 & 4.25 & 5.1 & 20 \\
\hline 3 & Betula utilis & 3.31 & 4.4 & 4.20 & 5.2 & 28 \\
\hline 4 & Ginkgo biloba & 4.11 & 4.16 & 4.25 & 5.12 & 26 \\
\hline 5 & Michelia alba & 3.23 & 3.29 & 4.10 & 4.25 & 27 \\
\hline 6 & Juglans regia & 4.11 & 4.17 & 4.30 & 5.10 & 23 \\
\hline 7 & Platanus acerifolia & 4.11 & 4.16 & 4.30 & 5.13 & 27 \\
\hline 8 & Populus szechuanica var. tibetica & 4.5 & 4.5 & 4.20 & 5.2 & 27 \\
\hline 9 & Malus halliana & 3.20 & 3.20 & 4.13 & 4.24 & 35 \\
\hline 10 & Salix alba & 3.5 & 3.5 & 3.17 & 3.26 & 21 \\
\hline 11 & Salix cheilophila & 4.4 & 4.4 & 4.18 & 4.28 & 24 \\
\hline 12 & Myricaria elegans & 4.9 & 4.18 & 5.9 & 5.26 & 34 \\
\hline 13 & Ulmus pumila 'jinye' & 3.27 & 4.8 & 4.23 & 4.31 & 23 \\
\hline 14 & Morus mongolica var. diabolica & 4.16 & 4.19 & 5.5 & 5.19 & 30 \\
\hline 15 & Rosa xanthina & 4.24 & 4.30 & 5.10 & 5.19 & 19 \\
\hline 16 & Rosa omeiensis & 3.31 & 4.4 & 4.22 & 5.7 & 33 \\
\hline 17 & Amygdalus mira & 3.30 & 3.30 & 4.14 & 4.25 & 26 \\
\hline 18 & Amygdalus triloba & 3.11 & 3.11 & 3.25 & 4.9 & 29 \\
\hline 19 & Prunus cerasifera f. atropurpurea & 3.25 & 4.1 & 4.13 & 4.22 & 21 \\
\hline 20 & Pyrus bretschneideri & 3.22 & 4.3 & 4.18 & 5.1 & 28 \\
\hline 21 & Armeniaca mume var. bungo & 3.20 & 4.9 & 4.20 & 4.28 & 19 \\
\hline 22 & Cerasus serrulata var. lannesiana & 3.16 & 4.4 & 4.17 & 5.1 & 27 \\
\hline 23 & Malus pumila & 3.20 & 4.7 & 4.26 & 5.3 & 26 \\
\hline 24 & Malus halliana & 3.2 & 3.2 & 3.22 & 3.29 & 28 \\
\hline 25 & Malus baccata & 3.23 & 4.4 & 4.19 & 5.1 & 27 \\
\hline 26 & Crataegus pinnatifida & 4.26 & 5.2 & 5.18 & 5.30 & 28 \\
\hline 27 & Sorbus rehderiana & 4.4 & 4.8 & 4.23 & 5.4 & 26 \\
\hline 28 & Spiraea canescens & 3.29 & 4.3 & 4.24 & 5.8 & 35 \\
\hline 29 & Sorbaria arborea & 3.29 & 4.4 & 4.23 & 5.12 & 38 \\
\hline 30 & Rubus biflorus var. biflorus & 4.11 & 4.16 & 4.29 & 5.9 & 23 \\
\hline 31 & $\begin{array}{c}\text { Sophora japonica var. japonica } \mathrm{f} . \\
\text { pendula }\end{array}$ & 4.16 & 4.25 & 5.11 & 5.20 & 25 \\
\hline 32 & Robinia pseudoacacia & 4.8 & 4.20 & 5.3 & 5.19 & 29 \\
\hline 33 & Cercis chinensis & 4.21 & 5.6 & 5.28 & 6.18 & 42 \\
\hline 34 & Wisteria sinensis & 4.25 & 4.25 & 5.12 & 5.26 & 31 \\
\hline 35 & Caragana bicolor & 5.6 & 5.11 & 5.28 & 6.18 & 30 \\
\hline 36 & Desmodium callianthum & 4.9 & 4.14 & 4.26 & 5.6 & 22 \\
\hline 37 & Piptanthus nepalensis & 3.5 & 3.13 & 3.22 & 3.29 & 16 \\
\hline 38 & Syringa oblata & 3.14 & 3.20 & 4.1 & 4.9 & 20 \\
\hline 39 & Fraxinus chinensis & 4.11 & 4.26 & 5.5 & 5.13 & 17 \\
\hline 40 & Chionanthus retusus & 4.18 & 4.25 & 5.5 & 5.13 & 18 \\
\hline 41 & Forsythia suspensa & 3.26 & 4.15 & 4.30 & 5.13 & 28 \\
\hline 42 & Chimonanthus praecox & 4.3 & 4.3 & 4.17 & 5.2 & 29 \\
\hline 43 & Swida alba & 3.22 & 3.29 & 4.13 & 4.24 & 26 \\
\hline 44 & Paeonia ludlowii & 3.31 & 4.5 & 4.20 & 5.1 & 26 \\
\hline 45 & $\begin{array}{c}\text { Hippophae rhamnoides subsp. } \\
\text { gyantsensis }\end{array}$ & 3.10 & 3.20 & 4.15 & 5.6 & 47 \\
\hline 46 & Berberis thunbergii var. atropurpurea & 3.13 & 3.13 & 3.29 & 4.10 & 28 \\
\hline 47 & Acer caudatum & 4.8 & 4.17 & 5.1 & 5.13 & 22 \\
\hline 48 & Acer palmatum cv.atropurpureum & 4.11 & 4.20 & 5.3 & 5.12 & 26 \\
\hline 49 & Celastrus stylosus & 3.28 & 4.12 & 4.28 & 5.10 & 28 \\
\hline 50 & Hypericum choisianum & 3.2 & 3.30 & 4.15 & 4.27 & 28 \\
\hline 51 & Zanthoxylum motuoense & 4.22 & 4.28 & 5.12 & 5.21 & 23 \\
\hline 52 & Lagerstroemia indica & 5.6 & 5.17 & 6.2 & 6.16 & 30 \\
\hline 53 & Punica granatum & 4.30 & 5.4 & 5.20 & 6.2 & 28 \\
\hline
\end{tabular}

Note: *: Phenological time is represented by the number of days from March 1 (Julian Day) 


\section{Results and analysis}

\section{Phenological phase observation on budding and leaf expansion}

It can be seen from Table 1 and Fig. 2 that the budding period of the 53 common landscape tree species in Nyingchi Prefecture lasts from the beginning of March to the beginning of May, and the concentration period is mid-to-late March (26 species, $49.06 \%$ ). The budding characteristics of different plant species vary greatly, with the earliest budding in Salix alba, Piptanthus nepalensis (March 5), while Caragana bicolor, Lagerstroemia indica have the latest budding (May 6), with a discrepancy of $62 \mathrm{~d}$ between the two.

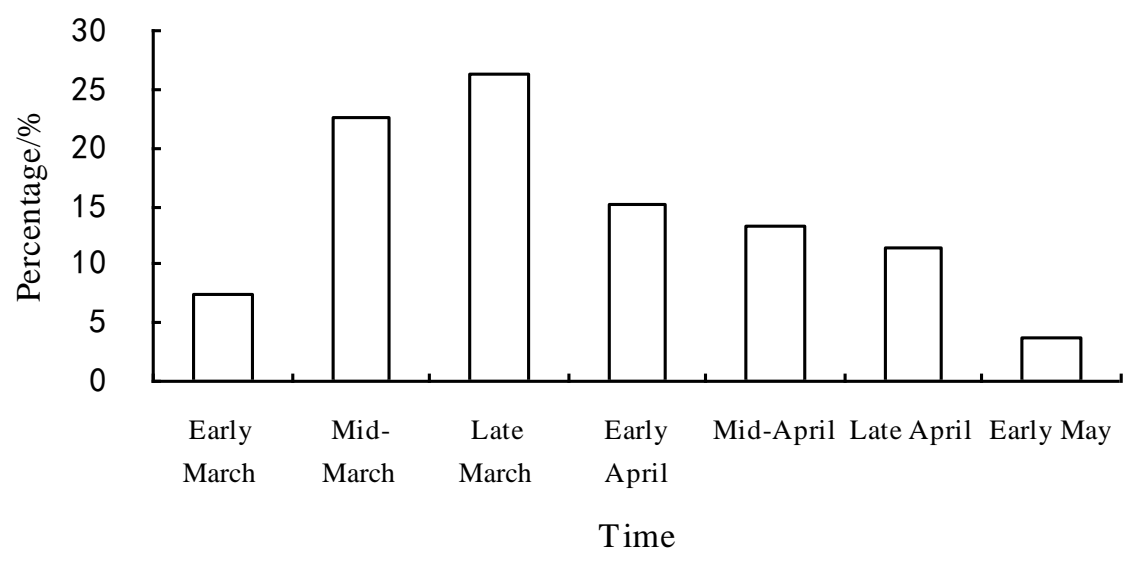

Figure 2. Budding characteristics of 53 landscape trees

\section{Phenological characteristics of leaf expansion}

It can be seen from Table 1 and Fig. 3 that the leaf expansion period of the 53 common landscape tree species lasts from the beginning of March to the middle of June. Initial stage of leaf expansion lasts from early March to mid-May. Where, Salix alba has the earliest initial leaf expansion (March 5), lagerstroemia indica has the latest initial leaf expansion (May 17), with a discrepancy of $73 \mathrm{~d}$ between the two. Peak period of leaf expansion lasts from mid-March to late May. Where, Salix alba is the earliest in peak leaf expansion (March 17), Caragana bicolor is the latest in peak leaf expansion (May 28), with a discrepancy of $72 \mathrm{~d}$ between the two. End of leaf expansion lasts from late March to mid-June. Where, Salix alba has the earliest end of leaf expansion (March 26), Caragana bicolor has the latest end of leaf expansion (June 18), with a discrepancy of $84 \mathrm{~d}$ between the two. The average duration of leaf expansion is $26.81 \mathrm{~d}$, which is relatively long. In terms of the duration of leaf expansion, the longest is Hippophae rhamnoides subsp. gyantsensis $(47 \mathrm{~d})$, the shortest is Piptanthus nepalensis (16 d), with a discrepancy of $31 \mathrm{~d}$ between the two.

The initial stage of leaf expansion is mainly concentrated in early April (14 species, $26.41 \%$ ) and mid-April (12 species, 22.64\%), the peak period of leaf expansion is mainly concentrated in mid-April (15 species, 28.30\%) and late April (14 species, $26.41 \%$ ), and the end of leaf expansion is mainly concentrated in mid-May (18 species, $33.96 \%$ ) and late May (12 species, 22.64\%). It provides a theoretical basis for the construction time to local landscape. 
The analysis shows that there exists a significant correlation between the initial stage of leaf expansion and budding period, the peak period of leaf expansion and the budding period, the end of leaf expansion and the budding period (Table 2). It indicates close correlation between leaf expansion time and budding time. Tree species with earlier budding period have earlier leaf expansion stage, the result is consistent with Zhao et al. (2016). The average interval between budding period and initial stage of leaf expansion is $7.11 \mathrm{~d}$. The result showed that: Some species had no budding period and they are mainly Salicaceae, such as Populus szechuanica var. Tibetica,Malus hallian, Salix alba et al. On the other hand, the longest interval between budding period and initial stage of leaf expansion was Hypericum choisianu (28 d). In addition, the duration of leaf expansion is significantly correlated with the end of leaf expansion, but not with other parameters of leaf phenology.

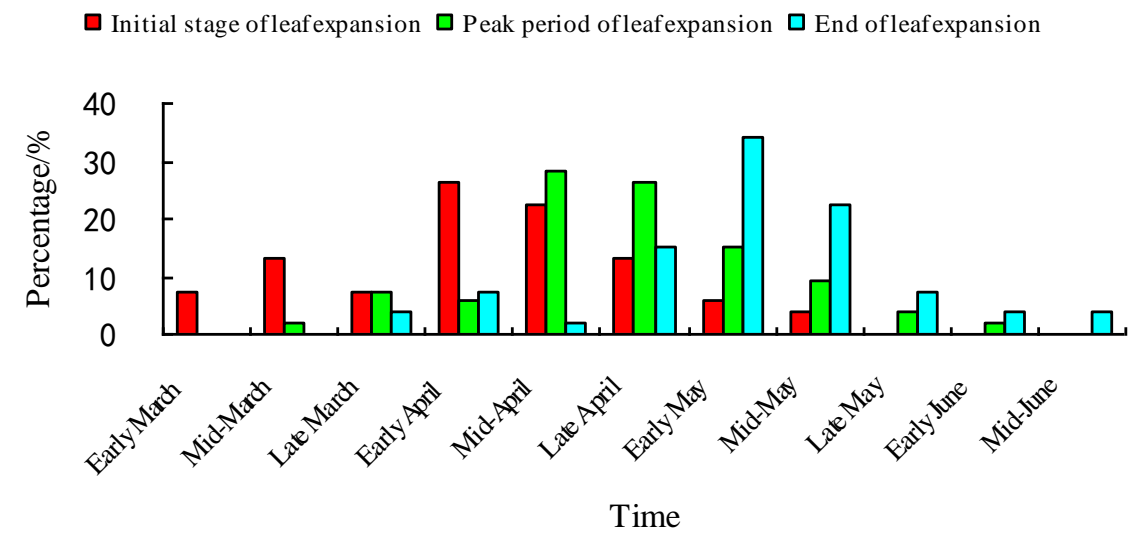

Figure 3. Leaf expansion characteristics of 53 landscape trees

Table 2. Total variance of the original variables explained in leaf phenology PCA of each tree species

\begin{tabular}{c|c|c|c|c|c}
\hline & Budding period & $\begin{array}{c}\text { Initial stage of } \\
\text { leaf expansion }\end{array}$ & $\begin{array}{c}\text { Peak period of } \\
\text { leaf expansion }\end{array}$ & End of leaf expansion & $\begin{array}{c}\text { Leaf extension } \\
\text { duration }\end{array}$ \\
\hline Budding period & 1 & $0.943^{* *}$ & $0.921^{* *}$ & $0.897^{* *}$ & 0.032 \\
Initial stage of leaf expansion & $0.943^{* *}$ & 1 & $0.973^{* *}$ & $0.943^{* *}$ & 0.010 \\
Peak period of leaf expansion & $0.921^{* *}$ & $0.973^{* *}$ & 1 & $0.982^{* *}$ & 0.203 \\
End of leaf expansion & $0.897^{* *}$ & $0.943^{* *}$ & $0.982^{* *}$ & 1 & $0.342^{*}$ \\
Leaf extension duration & 0.032 & 0.010 & 0.203 & $0.342^{*}$ & 1 \\
\hline
\end{tabular}

Note: $* * P<0.01, * P<0.05$

\section{Leaf phenology classification of 53 tree species}

According to the classification of phenological differences between tree species, to more clearly study the occurrence and duration of phenology of different tree species, this study conducted principal component analysis on budding and leaf expansion phenology of 53 tree species (Table 3). The analysis shows that the two main components of budding period and initial stage of leaf expansion play a significant role, with a contribution rate of $77.203 \%$ and $20.908 \%$, respectively, and the cumulative variance is $98.111 \%$. At the same time, it can be seen from Table 4 that the budding and leaf expansion parameters of the first principal component have high factor loading, 
which can represent the budding period, the initial stage, the peak and the end of leaf expansion respectively. Duration of leaf expansion in the second principal component has a higher factor loading, which can represent the duration of leaf expansion. The results are consistent with the correlation analysis (Table 2) between the various phenological parameters.

From the results of the above correlation analysis combined with Fig. 4, the leaf phenology of the 53 tree species can be divided into five categories. First, according to leaf budding time, there are three types of early, middle and late budding, each of which can be further divided into two categories according to the duration of leaf expansion.

Category 1: Early budding - short-medium duration of leaf expansion. The budding time is concentrated on March 5 and 6, and the leaf duration is 16 28 d. The tree species include Salix alba, Piptanthus nepalensis, and Malus halliana (5.66\%). Where, Piptanthus nepalensis has the shortest duration of leaf expansion among the 53 species $(16 \mathrm{~d})$.

Table 3. Correlation coefficients matrix for phenological parameters

\begin{tabular}{c|ccc|ccc}
\hline \multirow{2}{*}{ Component } & \multicolumn{3}{|c|}{ Initial eigenvalue } & \multicolumn{3}{c}{ Extraction sum of squared load } \\
\cline { 2 - 6 } & Total & Variance \% & Cumulative \% & Total & Variance \% & Cumulative \% \\
\hline 1 & 3.860 & 77.203 & 77.203 & 3.860 & 77.203 & 77.203 \\
2 & 1.045 & 20.908 & 98.111 & 1.045 & 20.908 & 98.111 \\
3 & 0.084 & 1.678 & 99.789 & & & \\
4 & 0.011 & 0.211 & 100.000 & & \\
5 & 0.005 & 0.110 & 100.000 & & \\
\hline
\end{tabular}

Table 4. Statistics of the first 2 PCs of leaf phenology for each tree species

\begin{tabular}{c|c|c}
\hline & PC1 & PC2 \\
\hline Budding period & 0.953 & -0.174 \\
Initial stage of leaf expansion & 0.977 & -0.189 \\
Peak period of leaf expansion & 0.992 & 0.006 \\
End of leaf expansion & 0.986 & 0.148 \\
Duration of leaf expansion & 0.202 & 0.979 \\
\hline
\end{tabular}

Category 2: Early budding-long duration of leaf expansion. There is only one species (1.89\%), i.e. Hippophae gyantsensis, whose budding time is March 10, and the duration of leaf expansion is the longest ( $47 \mathrm{~d}$ ) among the 53 tree species.

Category 3: Medium budding -medium-short duration of leaf expansion. The budding time is concentrated between March 11 to April 16, and the duration of leaf expansion is $17 \sim 38 \mathrm{~d}$. There are 40 tree species (75.47\%), including Larix griffithii, Populusszechuanicavar.tibetica, Hypericum choisianum, Prunus mira, Desmodium callianthum Franch, Morus mongolica var. Diabolica, Celastrus stylosus, Sorbus rehderiana, Acer caudatum, Sorbaria arborea, Myricaria elegans Royle, Salixaureo-pendula, Cerasus yedoensis, Syringa oblata, etc.

Category 4: Late budding - medium-short duration of leaf expansion. The budding time is concentrated on April 18-May 6, and the duration of leaf expansion is $18 \sim 31 \mathrm{~d}$. There are 8 tree species (15.09\%), including Chionanthus retusus, Rosa xanthina, Zanthoxylum motuoense, Fructus Crataegi, Chinese wisteria, Caragana bicolor, 
Lagerstroemia indica. Where, Lagerstroemia indica has the latest end of leaf expansion among the 53 tree species (June 16).

Category 5: Late budding- long duration of leaf expansion. There is only one species $(1.89 \%)$, i.e. Cercis chinensis, whose budding time is April 21, and the duration of leaf expansion is $42 \mathrm{~d}$.

It can be seen from the above that the spring leaf phenology of the landscape tree species in the prefecture mainly features "medium budding-medium-short duration of leaf expansion". The type accounts for $75.47 \%$ of the investigated tree species.

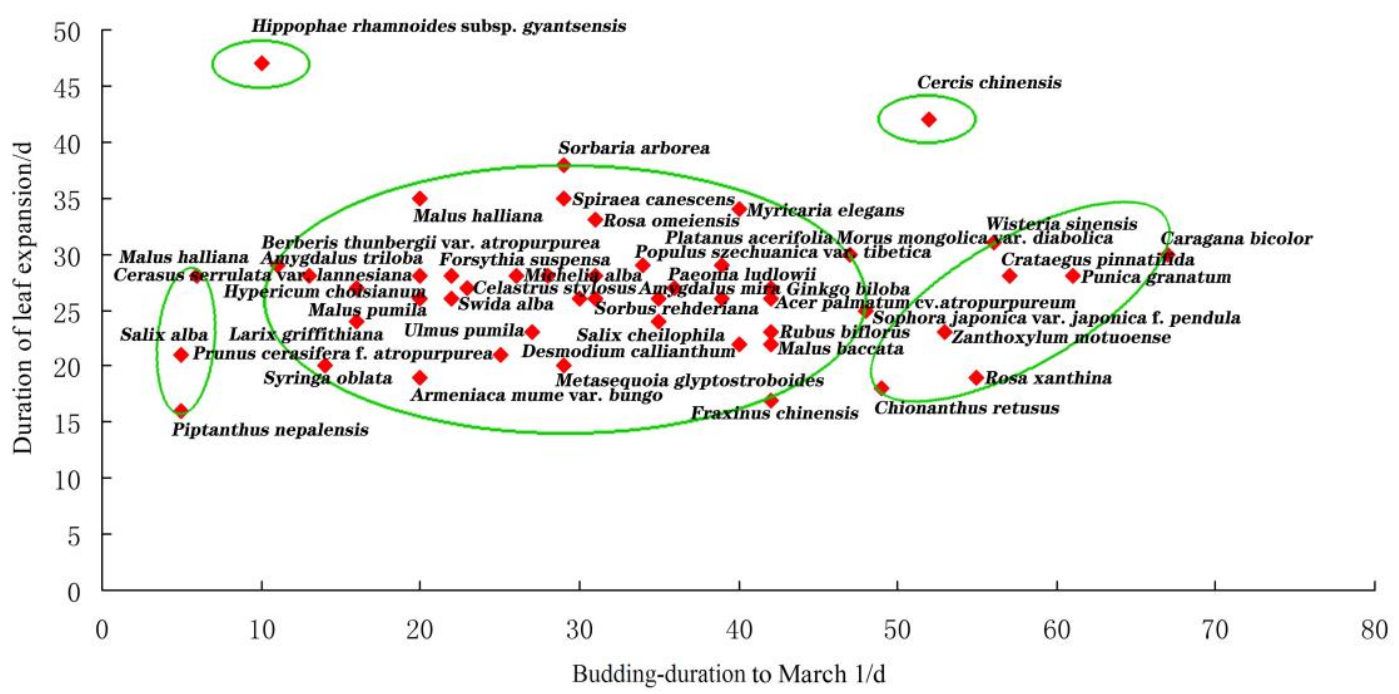

Figure 4. Scatter plot of budding-duration of leaf expansion

\section{Discussion}

\section{Sequential correlation of budding phenology}

Zhao et al. (1979) proposed sequential correlation law of phenology through correlation analysis on tree phenology, who believed that phenological phenomena were related to the emergence of another phenological phenomenon. Cao and Liu (1999) conducted clustering analysis on 16 broad-leaved trees in Nanchang Arboretum for the management of forest culture time, while phenological combination of urban landscape trees was not much studied. The phenological studies in Europe show that the phenology of plants in the mid-latitudes such as budding and leaf expansion depends mainly on temperature (Sparks et al., 2000; Kramer et al., 2000; Chmielewski and Rotzer, 2001; Fitter et al., 2002; Broadhead et al., 2003), which is consistent with the conclusion of phenological study by Zhang et al. (1995) on Beijing. Nyingchi Prefecture located in the western part of China has relatively cold winter and spring. Temperature is the dominant factor affecting the budding and leaf expansion of trees. The various trees have concentrated budding and leaf expansion, with difference weakened by the dominant environmental factors, which is consistent with phenological study by Hu et al. (2016) on Shenyang.

With the recent increase of temperature, the plant growth season is prolonged and the spring phenology is advanced (Ahas et al., 2000; Anderson et al., 2005). At present, phenological research focuses on the relationship between phenology and climate 
change (Zhao et al., 1983; Menzel and Fabian, 1999; Schwartz and Reiter, 2000; Walther et al., 2000), phenology response to the environment (Snyder et al., 2001; Augspurger, 2008; Ahas, 2009). Constructing different predictive models (Li et al., 2000) for corresponding studies on communities and above is an important aspect of future phenological research.

\section{Budding phenology and afforestation}

Due to its special natural environmental conditions, Tibet has difficulty in afforestation, and the budding period of different tree species varies greatly. "Not high survival rate of afforestation, frequent phenomenon of repeated replanting", "no tree despite years of afforestation" are prominent problems in most areas for a long time (Liu et al., 2015; Zhang et al., 2016). Afforestation faces easy damage and difficult recovery, further increasing the pressure on Tibet's ecological environment.

Practice has proved that planting before leaf budding can significantly improve the afforestation survival rate of local landscape tree species. Examples of planting failures are frequent in Nyingchi Prefecture due to improper planting seasons (especially old tree transplants). According to the leaf phenological characteristics of the landscape trees in the Prefecture, the first and second types of tree species with earlier budding are recommended to be planted in late February. The third type of tree with moderate budding time is suitable for planting in March. Where, Larix griffithii, Prunus triloba, Syringa oblate, etc. with relatively early budding are suitable for planting in early March, while Morus mongolica Schneid, Chinese pagoda tree, Fraxinus chinensis, etc. with relatively late budding are suitable for planting in late March. The 4th and 5th category of tree species with the latest budding time are suitable for planting before mid-April. Recent years have witnessed vigorous development of ecological construction projects in the Prefecture. Under the premise of respecting nature, adapting to local conditions and planting at the right time can effectively improve survival rate of landscape tree planting, enhance the water source conservation function, effectively curb sandstorm hazard, especially the "air drying phenomenon" prevalent in the Prefecture (Liu et al., 2015), and improve the green looking ratio and the ornamental and ecological effects, greatly promote the gradual transition of the Prefecture's green space from "single-layer structure" to "multi-layer ecological structure", thus creating unique plateau urban garden landscape in Tibet.

\section{Leaf expansion phenology and landscape construction}

Studies have shown concentrated phenology in Nyingchi Prefecture. There are few tree species with early budding and late budding. Medium budding time is the main case, which is mainly concentrated in mid-March to mid-April. This is not conducive to seasonal aspect and continuous landscape construction. Garden landscaping should consider the influence of plant budding period, seasonal distribution and duration of leaf expansion on landscaping. The landscape trees with early leaf expansion and late leaf expansion should be rationally combined in planting to optimize plant collocation, which can enrich seasonal scenery in spring, extend the viewing time, enhance ecological benefits and also provide biological basis for the local garden planning and design, cultivation management and plant configuration to form rich urban landscape. It is suggested that 5 types of leaf phenological species be combined with each other to better construct local characteristic garden landscapes and enrich the community levels. 


\section{Garden phenology forecast}

With the development of local tourism, Nyingchi Prefecture has become an international tourism city with increasingly developed relevant tourism industry. Affected by natural factors such as climate fluctuations, phenology of local landscape plants varies from year to year. Studies on garden phenology to accumulate relevant phenological data is conducive to the accurate implementation of relevant garden phenology prediction work, thus providing guidance for the annual "Peach Blossom Festival", garden visit, travel and tourists' sightseeing.

\section{Conclusion}

1). Budding and leaf expansion phenology features long duration. The budding period of the 53 common landscape tree species in Nyingchi Prefecture is concentrated in the middle and late March, with a total duration of $62 \mathrm{~d}$ and an average duration of $7.56 \mathrm{~d}$. The entire leaf expansion period lasts from early March to mid-June, with a total duration of $108 \mathrm{~d}$ and an average duration of $26.81 \mathrm{~d}$. The total duration and average duration of budding and leaf expansion periods are longer than those of Shanghai (Zhao et al., 2016), which may be related to the local cold climate and the difference between seed selection objects. Therefore, it is recommended the afforestation should be completed before mid-April according to the leaf phenological characteristics of Nyingchi Prefecture.

2) There is a significant correlation between the initial stage of leaf expansion and budding period, the peak period of leaf expansion and the budding period, and the end of leaf expansion and budding period. The duration of leaf expansion is significantly correlated with the end of leaf expansion, but not with other parameters of leaf phenology. It is recommended to arrange the seasonal landscape according to the leaf expansion characteristics of the tree species.

3) The leaf phenological type is mainly "medium budding - medium-short duration of leaf expansion". Corresponding suitable planting time was proposed based on tree species with different phenological types in Nyingchi Prefecture.

Acknowledgements. The project was funded by the National Natural Science Foundation of China (51568059).

\section{REFERENCES}

[1] Ahas, R., Jaagus, J., Aasa, A. (2000): The phenological calendar of Estonia and its correlation with mean air temperature. - Int. J. Biometeorol 44(4): 159-166.

[2] Ahas, R. (2009): Long term phyto-, ornitho- and ichthyo phenological time series analyses in Estonia. - International Journal of Biometeorology 42: 119-127.

[3] Anderson, D. P., Nordheim, E. V., Moermond, T. C., Gone, B. Z. (2005): Factors influencing tree phenology in TaÏ National Park, Côte d'lvoire. - Biotropica. Côte d'lvoire 37: 631-640.

[4] Augspurger, C. K. (2008): Early spring leaf out enhances growth and survival of sapling in a temperate deciduous forest. - Oecologia 156: 281-286.

[5] Bai, J., Ge, Q. S., Dai, J. H., Wang, Y. (2016): Relationship between woody plants phenology and climate factors in Xi'an, China. - Chinese Journal of Plant Ecology 34(11): 1274-1282. 
[6] Broadhead, J. S., Ong, C. K., Black, C. R. (2003): Tree phenology and water availability in semi-arid agroforestry systems. - Forest Ecology and Management 180: 61-73.

[7] Cao, Z. B., Liu, G. Z. (1999): Study on phenological characteristics of 16 fine broadleaved tree species. - Jiangxi Forestry Science and Technology 4: 1-3.

[8] Chen, S. P., Dai, X. Z., Guo, T. J., Zhuang, Q. Q. (2015): Phenophase of landscape trees and its application in disposition of plants in Changchun City. - Journal of Jilin Agricultural University 33(2): 189-194.

[9] Chmielewski, F. M., Rotzer, T. (2001): Response of tree phenology to climate change across Europe. - Agric. For. Meteorol 108(2): 101-112.

[10] Fitter, A. H., Fitter, R. S. (2002): Rapid changes in flowering time in British plants. Science 296: 1687-1691.

[11] Gu, A. Z., Zhang, H. L. (2015): The phenological characteristics of twenty major tree species of flower in the spring in Hohhot. - Northern Horticulture 12: 78-80.

[12] Hu, J. B., Xu, W. D., Chen, W., He, X. Y., Wen, H. (2016): Phenological analysis of main tree species in Shenyang urban forest. - Chinese Journal of Ecology 25(12): 14551459.

[13] Kramer, K., Leinonen, I., Loustau, D. (2000): The importance of phenology for the evaluation of impact of climate change on growth of boreal, temperate and Mediterranean forests ecosys-tems: An overview. - Int. J. Biometeorol 44(2): 67-75.

[14] Li, R. P., Zhou, G. S., Yan, Q. L. (2015): Study on plants phonological model. - Chinese Journal of Agrometeorology 26(4): 210-214.

[15] Liu, G. R. (2013): Phenological observation on common garden plants in Hengshui City. - Hubei Agricultural Sciences 52(16): 3884-3888.

[16] Liu, Z. N., Zhou, P., Pan, G., Fang, J. P., Wang, W., Zhang, H. F. (2015): Investigation and application research of landscape plants in Tibet of Shigatse City. - Northern Horticulture 20(29): 74-80.

[17] Liu, Z. N., Zhou, P., Yao, X. Z., Bao, L. Y. (2015): Research about the woody landscape plants' introduction in Linzhi Preferecture of Tibet. - Journal of Sichuan Agricultural University 23(29): 208-213.

[18] Liu, Z. N., Zhang, H. F., Wang, W., Zhou, P., Hao, W. Y., Xu, J. (2017): Resources of Colored-leaf Trees and Their Phenological Ornamental Characteristics in Linzhi City. Journal of Northwest Forestry University 32(4): 266-273.

[19] Ma, H. P., Zhu, X. L., Yang, X. L., Pan, G., Jin, Z. T. (2010): Study on the phenology characteristics of Juglans regia L. in Linzhi area of Tibet. - Journal of Anhui Agricultural Sciences 38(33): 18960-18962.

[20] Menzel, A., Fabian, P. (1999): Growing season extended in Europe. - Nature 397(6721): 659.

[21] Nyingchi, S. B. (2014-2019): Nyingchi statistical yearbook. - China Statistics Press, Beijing.

[22] Ran, G. H., He, Q. Y., Fan, S. H., Wang, D. (2013): Analysis of precipitation agricultural climate resources in Linzhi area. - Agriculture and Technology 1: 142-144.

[23] Schwartz, M. D., Reiter, B. E. (2000): Changes in North American spring. - Int. J. Climatol 20(8): 929-932.

[24] Snyder, R. L., Spano, D., Duce, P. (2001): Temperature data for phenological models. Int. J. Biometeorol 45(4): 178-183.

[25] Sparks, T. H., Jeffree, E. P., Jeffree, C. E. (2000): An examination of the relationship between flowering times and temperature at the national scale using long-term phenological records from the UK. - Int J Biometeorol 44: 82-87.

[26] Walther, G. R., Post, E., Convey, P. (2002): Ecological responses to recent climate changes. - Nature 416: 389-395.

[27] Wan, M. W., Liu, X. Z. (1979): Phenological observation method in China. - Science Press, Beijing. 
[28] Xue, L. S., Luo, D. Q. (2014): Relationship analysis on phenological characteristics of Paeonia ludlowii with its main meteorological factors. - Guangdong Agricultural Sciences 7: 43-47.

[29] Zhang, F. C. (1985): Phenology. - China Meteorological Press, Beijing.

[30] Zhang, F. C. (1995): Effects of global warming on plants phenological everts in China. Acta Geographica Sinica 50(5): 402-409.

[31] Zhang, C. Y. (2016): Afforestation in Lasha river basin. - Forestry Construction 6: 29-32.

[32] Zhang, Z. X., Huang, Y. H., Wang, Y. X., Ye, J. Z., Li, X. L., Jiang, A. G. (2016): Investigation and application of flowering phenology of landscape plants in Nanjing. Guizhou Agricultural Sciences 42(12): 195-198.

[33] Zhang, M. Q., Yang, G. D., Zhang, L. (2018): Study on season aspect characteristics in Beijing City. - Journal of Capital Normal University (Natural Science Edition) 29(5): 6265.

[34] Zhao, F. C. (1983): Effects of global worming on plant phenological everts in China. Acta geographica sinica 50(5): 402-410.

[35] Zhao, X. L., Shi, C. Y., He, B., Ran, W. R., Cai, Y. L. (2016): Spring phenological characteristics and phenophase classification of landscape greening tree species in Changming Island of Shanghai. - Chinese Journal of Ecology 32(9): 2275-2280.

[36] Zhu, K. Z., Wan, M. W. (1980): Phenology (Enlarged edition). - Science Press, Beijing. 